\title{
Correction: Medication Adherence Reminder System for Virtual Home Assistants: Mixed Methods Evaluation Study
}

Cynthia F Corbett ${ }^{1,2}$, PhD, RN, FAAN; Elizabeth M Combs ${ }^{1,2}$, BA, MA; Peyton S Chandarana ${ }^{2,3}$, BSE; Isabel Stringfellow ${ }^{2,4,5}$; Karen Worthy $^{1}$, MPH, PhD, RN, CNE; Thien Nguyen ${ }^{1,2}$, BSN; Pamela J Wright ${ }^{1,2}$, MEd, MS, RN, CEN; Jason M O'Kane ${ }^{2,3}, \mathrm{PhD}$

${ }^{1}$ College of Nursing, University of South Carolina, Columbia, SC, United States

${ }^{2}$ Center for Advancing Chronic Care Outcomes through Research and Innovation, College of Nursing, University of South Carolina, Columbia, SC, United States

${ }^{3}$ College of Engineering and Computing, University of South Carolina, Columbia, SC, United States

${ }^{4}$ Arnold School of Public Health, University of South Carolina, Columbia, SC, United States

${ }^{5}$ South Carolina Honors College, Columbia, SC, United States

\section{Corresponding Author:}

Cynthia F Corbett, PhD, RN, FAAN

College of Nursing

University of South Carolina

1601 Greene St

Columbia, SC, 29208

United States

Phone: 18035766275

Email: corbett@sc.edu

\section{Related Article:}

Correction of: https://formative.jmir.org/2021/7/e27327

(JMIR Form Res 2022;6(1):e36381) doi: 10.2196/36381

In "Medication Adherence Reminder System for Virtual Home Assistants: Mixed Methods Evaluation Study" (JMIR Form Res 2021;5(7):e27327), three errors were noted.

Due to a system error, the name of one author, Cynthia F Corbett, was replaced with the name of another author on the paper, Elizabeth M Combs. In the originally published paper, the order of authors was listed as follows:

Elizabeth M Combs, Elizabeth M Combs, Peyton S Chandarana, Isabel Stringfellow, Karen Worthy, Thien Nguyen, Pamela J Wright, Jason M O'Kane

This has been corrected to:

Cynthia F Corbett, Elizabeth M Combs, Peyton $S$ Chandarana, Isabel Stringfellow, Karen Worthy,

Thien Nguyen, Pamela J Wright, Jason M O'Kane

In the originally published paper, the ORCID of author Cynthia F Corbett was incorrectly published as follows:
0000-0002-2254-6958

This has been corrected to:

0000-0003-2706-2116

In the originally published paper, the email of the Corresponding Author was incorrectly published as follows:

combsel@email.sc.edu

This has been corrected to:

corbett@sc.edu

The correction will appear in the online version of the paper on the JMIR Publications website on January 27, 2022, together with the publication of this correction notice. Because this was made after submission to PubMed, PubMed Central, and other full-text repositories, the corrected article has also been resubmitted to those repositories. 
This is a non-peer-reviewed article. Submitted 12.01.22; accepted 12.01.22; published 27.01.22.

Please cite as:

Corbett CF, Combs EM, Chandarana PS, Stringfellow I, Worthy K, Nguyen T, Wright PJ, O'Kane JM

Correction: Medication Adherence Reminder System for Virtual Home Assistants: Mixed Methods Evaluation Study

JMIR Form Res 2022;6(1):e36381

URL: https://formative.jmir.org/2022/1/e36381

doi: $\underline{10.2196 / 36381}$

PMID:

(C) Cynthia F Corbett, Elizabeth M Combs, Peyton S Chandarana, Isabel Stringfellow, Karen Worthy, Thien Nguyen, Pamela J Wright, Jason M O'Kane. Originally published in JMIR Formative Research (https://formative.jmir.org), 27.01.2022. This is an open-access article distributed under the terms of the Creative Commons Attribution License (https://creativecommons.org/licenses/by/4.0/), which permits unrestricted use, distribution, and reproduction in any medium, provided the original work, first published in JMIR Formative Research, is properly cited. The complete bibliographic information, a link to the original publication on https://formative.jmir.org, as well as this copyright and license information must be included. 